\title{
Measuring the car ownership impact of free-floating car-sharing A case study in Basel, Switzerland
}

\author{
Journal Article \\ Author(s): \\ Becker, Henrik; Ciari, Francesco; Axhausen, Kay W. (1) \\ Publication date: \\ 2018-12 \\ Permanent link: \\ https://doi.org/10.3929/ethz-b-000283371
}

Rights / license:

In Copyright - Non-Commercial Use Permitted

Originally published in:

Transportation Research Part D: Transport and Environment 65, https://doi.org/10.1016/j.trd.2018.08.003 


\title{
Measuring the Car Ownership Impact of Free-Floating Car-Sharing - A Case Study in Basel, Switzerland
}

\author{
Henrik Becker ${ }^{\mathrm{a}, *}$, Francesco Ciari ${ }^{\mathrm{a}, \mathrm{b}}$, Kay W. Axhausen ${ }^{\mathrm{a}}$ \\ ${ }^{a}$ ETH Zurich, Institute for Transport Planning and Systems, Stefano-Franscini-Platz 5, 8093 Zurich, \\ Switzerland \\ ${ }^{b}$ LIFE Centre for Climate, Energy and Society, Joanneum Research, 8020 Graz, Austria
}

\begin{abstract}
Free-floating car-sharing schemes operate without fixed car-sharing stations, ahead reservations or return-trip requirements. Providing fast and convenient motorization, they attract both public transport users and (former) car-owners. Thus, their impact on individual travel behavior depends on the user type. Estimating the travel behavior impact of these systems therefore requires quantitative data. Using a two-wave survey approach (shortly after launch of the scheme plus one year later) including travel diaries, this research indicates that (due to their membership) $6 \%$ of the free-floating car-sharing customers reduce their private vehicle ownership. Moreover, the results suggest that freefloating car-sharing both complements and competes with station-based car-sharing.
\end{abstract}

Keywords: car-sharing, car ownership, environmental impact, substitution, multivariate probit, latent variables

\footnotetext{
*Corresponding author
}

Email address: henrik.becker@ivt.baug.ethz.ch (Henrik Becker)

Preprint submitted to Transportation Research Part D 


\section{Introduction}

Since its first implementation in Ulm, Germany, in 2009, free-floating car-sharing has expanded rapidly around the globe [1. Instead of relying on fixed car-sharing stations, free-floating car-sharing schemes usually make use of public parking spaces within 5 a designated, citywide service area. Customers can locate and book the closest available vehicle using a smartphone app. At the end of their trip, they can leave the vehicle on any public parking space. Free-floating car-sharing thus offers flexible one-way trips, overcoming key limitations of traditional, station-based car-sharing schemes.

10 Because free-floating car-sharing schemes require access to public parking spaces, they are more dependent on the support of local authorities. However, concerned about a deteriorating traffic situation, many authorities limit the number of parking permits for free-floating vehicles. Before relaxing such restrictions, they ask for more detailed knowledge about the travel behavior impact of free-floating car-sharing.

Addressing this issue requires new research, because insights from previous studies on station-based car-sharing are in general not transferable to free-floating car-sharing, given their structural differences [2. Moreover, first attempts to determine the net impact on travel behaviour have failed due to a lack of quantitative data [3].

This paper reports on an approach, which was designed to allow quantification of the travel behaviour impact of free-floating car-sharing. The method is applied to a new free-floating car-sharing scheme launched in Basel, Switzerland, in August 2014. 


\section{Background}

\section{2.1. Free-Floating Car-Sharing}

Modern car-sharing dates back to the early 1990s and has seen exponential growth in both customers and fleet size since then [4]. The schemes offer their customers access to cars on an as-needed basis, representing a cheap alternative to a private vehicle - especially for households with relatively low annual mileage 5 . Originally, car-sharing op-

so erations were exclusively station-based; cars were available at predefined parking spaces (stations) and had to be returned to one of those stations at the end of the trip. While most schemes required the vehicles to be brought back to the start station (round-trip requirement), some of the schemes also permitted one-way trips. [6] suggest that such one-way car-sharing schemes are more attractive to customers, but less of a complement

35 to public transport than round-trip car-sharing.

By lifting the restriction of fixed car-sharing stations as well as allowing one-way trips, free-floating car-sharing is an even more flexible form of car-sharing. First launched in 2009, the number of customers and schemes has skyrocketed in recent years [1.

\section{2.2. Measuring Car-Sharing Impact}

The environmental and travel behaviour impact of (station-based) car-sharing has been the subject of various studies around the world. Despite different methodological setups, previous studies have consistently found that while a small group of car-sharing members increase their car use, their additional vehicle mileage is more than offset by

45 previous car-owners, who have substantially reduced their car ownership and travel in the course of their car-sharing membership [7. Moreover, it has been pointed out that the environmental impact exceeds the savings in vehicle miles, because - on average car-sharing vehicles consume significantly less energy than the private vehicles they replace [8].

50

One of the first comprehensive explorations of car-sharing travel behaviour impacts was conducted in Switzerland 9. In a survey, respondents were asked to report their travel behaviour both currently and retrospectively, prior to their car-sharing membership. Lacking any travel survey data, the study relied solely on respondents' estimates for their

${ }_{55}$ current and past vehicle miles travelled, without any knowledge about the accuracy of such estimates. Moreover, neglecting unobserved heterogeneity, changes in car-ownership and vehicle miles travelled were attributed to car-sharing membership, which probably inflated the actual effect [10. Furthermore, it must be assumed that a retrospective survey approach like this prompts recall bias [11, 12, particularly affecting estimates

${ }_{60}$ of vehicle miles travelled. Yet, because they impose a low response burden and require minimal administrative effort, similar methodologies have been adopted by many later studies [7, 13, 14, 15].

[16] and [17 were the first to address these limitations using a major methodological 65 innovation; in a longitudinal setting, they administered their survey to a panel in multiple waves to overcome recall bias. Moreover, the survey was augmented by a two-day travel diary to strengthen travel behaviour data validity. Finally, a control group was supposed to allow isolation of the actual impact of car-sharing membership from external 
effects. However, the control group suffered from self-selection issues, probably biasing the results.

Given the later appearance of free-floating car-sharing, there is not yet a great volume of scientific literature dealing with its environmental impact. While early studies predicted a significant reduction in car ownership and $\mathrm{CO}_{2}$ emissions [18 from free-floating

75 car-sharing, the actual impact seems to be more complex, as non-car-owners reduce bike, walk and public transit trips, but start to use a (shared) car instead [19].

Some of the early empirical data on the impact of free-floating car-sharing was published by the [3], citing results of a Car2go member survey. The results indicate a rather 80 small reduction in household vehicle holdings. The impact on mode choice remains unclear, given that $40 \%$ of the customers claimed to use private cars less often, but $50 \%$ of the respondents also stated that they used public transportation less frequently. A related approach conducted in Switzerland yielded similar results [2].

${ }_{85}$ Using a survey approach, as in [9, a recent study by [20] aimed to define the net impact of free-floating car-sharing. The study indicated a clear trend towards less car ownership and less vehicle miles travelled due to free-floating car-sharing. However, the impacts were calculated based on a non-representative sample. The approach was further enhanced by [21] and 22]. Again using a retrospective survey approach, they differentiated

90 the impact of free-floating car-sharing on the level of car-ownership by frequency of use, as well as selected socio-demographic variables. However, also in these cases, validity of the resulting car-ownership impacts may be limited due to response bias. An overview of the results of the discussed studies is given in Table A.4. In this research, the net impact of free-floating car-sharing is studied further using quantitative data on individual travel

95 behaviour.

\subsection{Survey method}

A common way to collect quantitative data on individual travel behaviour are travel diaries, which capture all activities and trips during a pre-defined survey period. As individual travel behaviour varies over the course of a week, the travel diary should ideally cover multiple days to account for such variation. However, collecting manual (paperbased or CAT [1] trip diaries was found to yield imprecise and missing data [23, 24. GPS-loggers would allow improvement of data quality, but come with high administration cost for the researcher [25]. The most recent alternative promising to reduce both the response burden and administrative effort while achieving a high data quality is smartphone-based GPS-tracking [26, 27, 28, 29. However, due to smartphone-based systems' novelty, only few surveys have employed them yet. A notable application to research in car-sharing was the German WiMobil-study [30, in which smartphone-based GPS tracking was used to study the travel patterns of car-sharing customers. However, since this was a cross-sectional study, no inferences on the travel behavior impact were 110 possible.

\footnotetext{
${ }^{1}$ computer-assisted telephone interview
} 


\section{Setup}

\subsection{Methodology}

The methodology used for this research builds on the approach used by 16. Its limitations are addressed by using a more representative control group and a smartphone-based GPS tracking system to collect travel diaries (i.e. quantitative data on travel behaviour). It uses a panel of two cohorts who were surveyed first shortly after the launch of the freefloating car-sharing scheme and again one year after. Part of each survey wave was a one-week travel diary. One cohort was drawn from members of the free-floating carsharing scheme, and the second was randomly drawn from the local driver's-licensed population (control group). The general idea of the setup is presented in Figure 1

To collect the travel diaries, Studio Mobilitd ${ }^{2}$, a smartphone-based, passive GPS-tracking system has been used. The system uses prompted recall for manual trip mode and purpose imputation by the respondents. In this setup, respondents simply download an app on their smartphone, which automatically tracks their daily trips using the built-in GPS-sensor. Although this allows only smartphone-holders to take part in the study, the validity of the results remains unaffected. As the free-floating car-sharing service can only be used by smartphone-owners, non-owners are excluded from the service by design.

The chosen setting allows a before-and-after comparison of travel behaviour. Moreover, the representative control group allows isolation of the actual free-floating car-sharing impact. Since no pre-registration in the free-floating car-sharing scheme was available, it was impossible to identify members before the launch of the scheme. Therefore, the first 35 stage of the survey was carried out 6 weeks after the launch of the scheme ${ }^{3}$ However, it is assumed that, in this short time frame, no substantial changes in travel behaviour took place. This assumption is supported by previous research indicating that the main effects of a car-sharing service occur within the first two years of its operation [17].

\subsection{Context}

The study was conducted in Basel, the third-largest city in Switzerland (approx. 160000 inhabitants). Basel is situated in the north-western part of the country and shares borders with both France and Germany. Divided by the river Rhine, its actual city centre is located in the southwest half of the city, although there is also substantial cultural and economic activity in the northeast parts of the city. Basel has a net influx

145 of commuters, with an average of 1.4 work places per inhabitant. With a car mode-share of $18 \%$ of all trips, it is the least car-oriented of the larger Swiss cities. In turn, it has relatively high mode shares for public transportation $(27 \%)$ and bike (16\%). Following this pattern, Basel also has the lowest degree of motorisation of the larger Swiss cities (352 registered cars per 1000 inhabitants). The low motorisation is powered by a dense 150 network of public transportation including rail, metro, tramways and buses. Still, the city has an estimated total of 100000 parking spaces (both private and public). While

\footnotetext{
${ }^{2}$ www.studio-mobilita.ch

${ }^{3}$ In most cases, the actual time between registration with the service and the survey was lower, because during the first months, uptake of the scheme increased over time.
} 


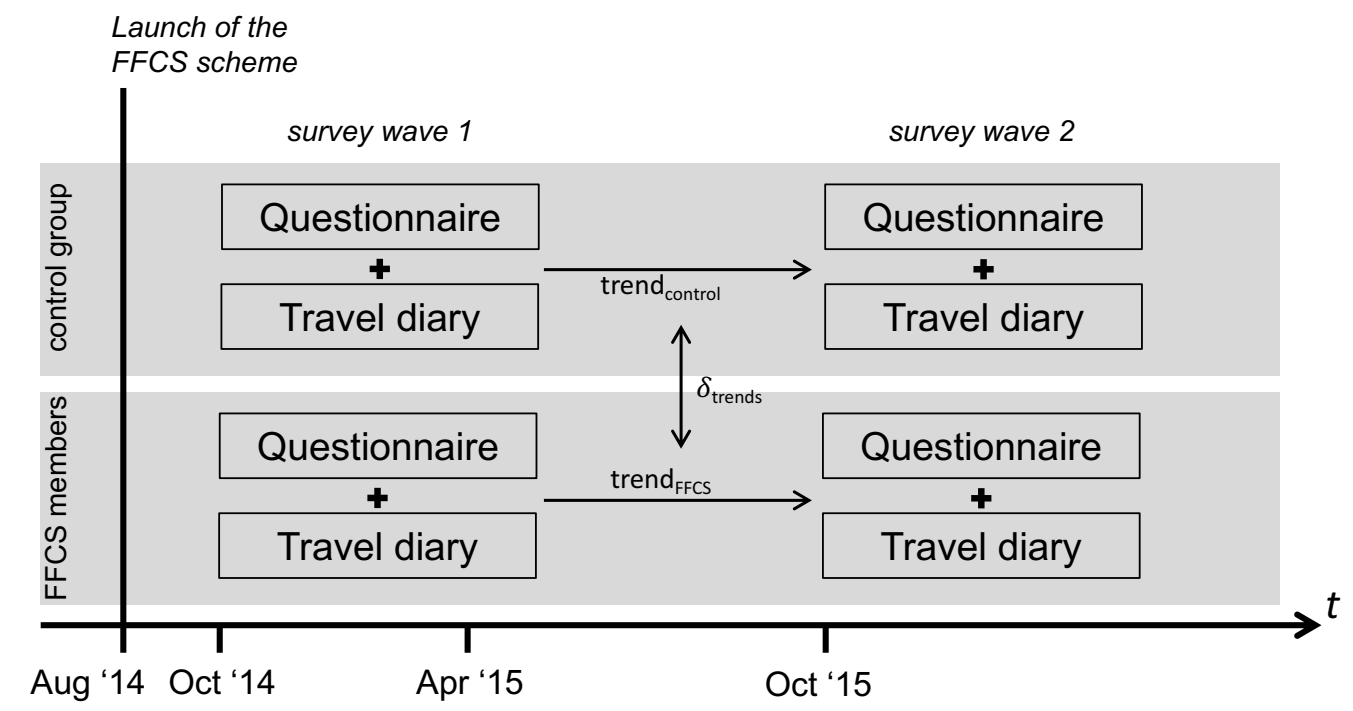

Figure 1: Study design

public on-street parking was free of charge for the public at the beginning of this study, the city of Basel has gradually moved towards either pricing on-street parking or making it exclusive for residents of the respective neighbourhoods. For more detailed information on the transport system in the city of Basel, the interested reader may refer to [31.

A free-floating car-sharing scheme was launched in Basel in late August 2014. Starting with 100 vehicles in the inner city of Basel as its operating area, it has since expanded to cover the whole canton of Basel-Stadt, as well as a small number of neighbouring municipalities. Meanwhile, the fleet size was increased to 120 vehicles. The system is open to anyone holding a drivers license. There is a 15 CHF registration fee, but no annual membership fees. Rentals are charged by the minute. 


\section{Data collection}

\subsection{Recruitment}

In total, 1218 free-floating members and 6000 members of the random sample were invited to take part in the study. Address lists of car-sharing members were made available by the operator; surface mail addresses for the random sample of the Canton Basel-Stadt population above legal age were provided by the Cantonal Statistical Office of Basel-Stadt.

170

Each survey wave consisted of two parts. The first was a questionnaire about sociodemographic attributes, attitudes and mobility behaviour; the second part was a weeklong travel diary using the system Studio Mobilita. Respondents were asked to complete the questionnaire by the end of the week of receipt and to keep the diary the week after. Details and instructions concerning the travel diary were given on completion of the questionnaire.

While car-sharing members were recruited via e-mail and were able to access the webbased survey using personalized web-links, members of the control group received the survey in pencil-and-paper format via surface mail, including a reply-paid envelope. For company policy reasons, it was not possible to contact car-sharing members via surface mail. However, for the control group, no e-mail addresses were available. This asymmetric setting may have given rise to selection bias, which was addressed by applying sample weights to the responses, as detailed later in this section.

185

Moreover, car-sharing members were initially only to be invited to the questionnaire. On completion of the questionnaire, respondents were automatically invited to take part in the travel diary and were promised a $20 \mathrm{CHF}$ (equivalent to $13 \mathrm{USD}$ at purchasing power parity) credit on their next car-sharing bill. In contrast, members of the control group received all the necessary information along with the questionnaire. As incentive, they were offered $20 \mathrm{CHF}$ in cash in return for their full participation.

Survey invitations for the first wave were administered to the respondents in weekly cycles between October and December 2014. Hence, the survey started about six weeks after the launch of the scheme in late August 2014. Invitations for the second wave were administered one year later, i.e. between October and December 2015. In the last week of each survey wave, reminders were sent out to all those car-sharing members who had failed to complete the survey by then. Respondents overdue in completing their mobility diary, were offered assistance. Moreover, given the relatively small initial growth rates in membership, free-floating car-sharing members having joined the service between January and March 2015 were invited to take the survey in early April 2015. They were treated as part of the first wave. In order to allow enough time to the second survey wave, respondents to the April-wave were invited to the second survey wave in November 2015. Overall, half of the respondents from the free-floating car-sharing group were

\footnotetext{
${ }^{4}$ The shorter time between the two waves for this part of the sample may result in a certain underestimation of the actual car-sharing impact.
} 
205 recruited at this later stage. Yet, given that the distribution of age, gender and income of this later group was not significantly different from the earlier wave in fall 2014 and that the weather was also comparable, the responses were pooled and treated as part of the first survey wave in late 2014.

\subsection{Data acquisition}

First-wave respondents needed an average of 18 minutes and second-wave respondents 15 minutes to complete the web-based survey. With this rather short survey time, fatigue effects causing response bias and reducing the likelihood of proceeding to the travel diary were minimized.

The response rates for the different survey waves are summarized in Table 1. In the first wave, 366 free-floating car-sharing members returned a complete questionnaire and 91 completed the travel diary. From the control group, 594 questionnaires and 226 travel diaries were collected. Only respondents, who completed the questionnaire in the first wave were invited to the second wave. The valid diaries consist of users who provided comparable diaries for both waves (see section 4.2 for details).

Compared to previous surveys [32, response rates shown in Table 1 were well within the expected range. The slightly higher response rate among free-floating car-sharers may be explained by the fact that they were contacted on behalf of a service they had recently joined and could therefore be regarded as pre-recruited.

In contrast, the response rate achieved for the diaries was much lower than expected. From earlier experiences, it was expected that around $80 \%$ of the respondents would proceed to the travel diary after having completed the questionnaire. However, the response rate turned out to be substantially lower. Based on respondents' feedback and the fact that almost all dropouts occurred when respondents had to confirm a data privacy declaration, the authors assume that this drop in response rate could be attributed, at least partly, to data privacy concerns.

Data collection was partly shared with 2, who use the 2015 cross-section of the questionnaires (sample extended with additional (new) respondents) to analyze user groups and usage patterns of free-floating and station-based car-sharing. The paper also presents a detailed analysis of the socio-demographic variables of the response groups.

\subsection{Data preparation}

Only completed questionnaires were considered for the analysis. Moreover, responses from car-sharing members who completed the survey in less than seven minutes (a third of the average time) were excluded. Finally, unreasonable answers were identified on a per-question basis (e.g. year of birth before 1900). Members of the control group not holding driver's licenses were excluded from the analysis, under the assumption that they were not within the car-sharing target group.

To correct for gender and age selection bias, statistical weights were applied to individual responses. The respective marginal distributions were obtained from address lists 
Table 1: Response rates per response group

\begin{tabular}{lrrrr}
\hline & \multicolumn{2}{c}{ first wave } & \multicolumn{2}{c}{ second wave } \\
\hline & free-floating & control group & free-floating & control group \\
\hline Invitations sent & 1218 & 6000 & 366 & 594 \\
\hline Surveys completed & 366 & 594 & 224 & 284 \\
with drivers license & 366 & 447 & $224^{a}$ & $209^{a}$ \\
Response rate of the eligible & $30 \%$ & $10 \%$ & $61 \%$ & $48 \%$ \\
\hline Diaries completed & $91^{b}$ & 226 & $52^{b}$ & 88 \\
Response rate of the eligible & $25 \%$ & $51 \%$ & $23 \%$ & $32^{\circ}$ \\
\hline Valid diaries & & $37^{c}$ & $35^{c}$ \\
Legs in valid diaries & & 2743 & 2332 \\
\hline$a:$ sample used for estimation of impact on car-ownership. & & \\
$b:$ sample used for analysis of use cases. & & \\
$c:$ sample available for estimation of impact on mode share. & & \\
\hline
\end{tabular}

provided by the operator for members and from a national travel survey [33] for the control group. Spatial distribution of homes was also studied. However, since only random deviations were found, spatial effects were omitted, given the excellent access to public transportation throughout the study area.

Records from the travel diaries were also carefully prepared for the analysis. In a first sep, all responses recording less than three full days per survey period were dropped and only the remaining diaries were regarded as complete. In a second step, respondents who completed the prompted recall for less than $75 \%$ of their trips were excluded. All remaining travel diaries were then carefully reviewed manually to ensure validity of the records and comparability of the two survey periods (e.g. to exclude holiday period effects). As shown in Table 1, relatively few valid diaries were left after this process. Still, for the control group, the key variables (number of trips, daily distance, mode share) matched the results of the national travel survey 33 for Basel. Therefore, the observations can be assumed valid and provide a deep insight into changes in individual travel behavior possibly induced by free-floating car-sharing. 


\section{Data analysis}

The setup would allow to study three key aspects of the travel behaviour impact of free-floating car-sharing: the impact on the level of car-ownership, on mode choice and on vehicle miles travelled. However, given the unexpectedly low turnout of valid travel diaries, the quantitative analysis on vehicle miles traveled had to be dropped $5^{5}$ Of the remaining two analyses, the first part is a quantitative panel-analysis of the survey data, while the second part provides qualitative insights into the travel diaries.

To determine the impact on car ownership, several approaches are introduced to account for existing intentions to buy or sell vehicles. The impacts of free-floating car-sharing are then calculated using difference-in-differences approaches, as well as a populationaveraged Poisson and negative-binomial model. Whilst a simple difference-in-difference method has already been employed by [16], a population-averaged Poisson or negativebinomial modeling approach is a widely used tool in count panel data analyses [34. Both approaches allow to control for exogenous variables, such as income or subscriptions for public transportation. For this analysis, only respondents with a drivers license, who did not report a change in their employment status, work location or home location between the two survey waves were considered, yielding a remaining 204 control group observations and 191 free-floating car-sharing members.

${ }_{285}$ The impact on mode use was studied using a qualitative analysis of the travel diaries. To this end, activity chains involving use of free-floating car-sharing were compared to similar activity chains from the same respondent, where free-floating car-sharing was not used. To the authors' best knowledge, no similar approach has been used by any previous car-sharing study. It provides new valuable insights into use of free-floating car-sharing.

\footnotetext{
${ }^{5}$ Given the large inter- and intra-person variability in travel behaviour, it cannot be assumed that such a small group was representative for the respective population.
} 


\subsection{Car Ownership Impact}

In a first step, data from the surveys was used to estimate the impact of the freefloating car-sharing scheme on car ownership levels. To this end, different ways of framing the impact on car-ownership were introduced and analysed.

295 It was established that, from the beginning, free-floating car-sharing members owned substantially fewer cars than the control group ( 0.27 vs. 0.84 vehicles per household in first survey wave) and this difference is significant $(t=-10.7)$. Within the first year of operation of the free-floating car-sharing scheme, both groups slightly decreased their levels of car ownership to 0.24 and 0.83 vehicles per household, although those reductions are not statistically significant.

The impact of free-floating car-sharing on household vehicle holdings can be assessed in two different ways. Either the actual level of car ownership in the second year can be compared to the level of car-ownership respondents reported in first-year survey or it can be compared to the level of car ownership, respondents had anticipated for the second year when asked in the first-year survey. In the following, the two references will be denoted as actual number of cars and anticipated number of cars. The actual number of cars represents the number of cars reported in the first survey wave. The anticipated number of cars is based on this actual number of cars to which one car was added or subtracted in case the respondent stated plans to buy or sell a car within twelve months from the first survey wave.

Introducing the anticipated number of vehicles as possible reference was motivated by the observation that $3 \%$ of the free-floating car-sharing members stated that they had planned to buy an additional car. Anticipated car ownership averaged at 0.29 vehicles per free-floating car-sharing household and at 0.80 vehicles per control group household. It is noteworthy that the control group intended to decrease their level of car ownership. This effect may be due to the introduction of parking fees for on-street parking throughout Basel city, which has been introduced in multiple steps between 2014 and 2016. However, again, within-group differences between anticipated and second-wave car-ownership levels are not significant.

Using a difference-in-differences approach, change in car ownership levels of the freefloating car-sharing households can be compared to the control group. While no significant effect was found comparing the second-wave level to the actual first-wave level of car ownership, using the anticipated level of car ownership yields a significant difference in differences $(t=-2.34)$. In this case, free-floating car-sharing members have decreased their level of car ownership compared to the control group by 0.07 vehicles per household.

However, a simple comparison of the group means does not necessarily reveal the true impact of a free-floating car-sharing membership, because the observed changes may also be due to fluctuations in other, e.g. socio-demographic characteristics. To correct for such influences, three covariates expected to have an impact on vehicle ownership were considered [35. As shown in Table 2, when controlling for household income, GA travel

335 card ownership (a subscription allowing unlimited use of public transportation across Switzerland) and home location (city centre vs. agglomeration), the difference in differ- 
Table 2: Difference-in-Differences Approach for Car Ownership

\begin{tabular}{|c|c|c|c|c|}
\hline \multirow[t]{2}{*}{ Reference } & \multicolumn{2}{|c|}{ actual car ownership } & \multicolumn{2}{|c|}{ anticipated car ownership } \\
\hline & Coeff. & $t$ & Coeff. & $t$ \\
\hline Household income $[\mathrm{kCHF}]$ & $0.028^{* * *}$ & 4.55 & $0.027^{* * *}$ & 4.45 \\
\hline GA travelcard & $-0.195 * * *$ & -3.58 & $-0.208^{* * *}$ & -3.82 \\
\hline City center home & $-0.134 * * *$ & -2.57 & $-0.133^{* *}$ & -2.53 \\
\hline$\overline{\text { Baseline diff. }}$ & $-0.535^{* * *}$ & -9.35 & $-0.479^{* * *}$ & -8.24 \\
\hline Follow-up diff. & $-0.614^{* * *}$ & -11.41 & $-0.611^{* * *}$ & -11.33 \\
\hline \multirow[t]{2}{*}{ Diff.-in-Diff. } & $-0.079^{*}$ & -1.89 & $-0.132^{* * *}$ & -3.06 \\
\hline & \multicolumn{2}{|c|}{$N=790$} & \multicolumn{2}{|c|}{$N=790$} \\
\hline Significance codes: 0.10 * & $0.01^{* * *}$ & & & \\
\hline
\end{tabular}

ences is significant for both reference cases: Free-floating car-sharing members reduced their level of car ownership by 0.08 cars compared to their actual earlier level (significant at the $10 \%$ level) and by a significant 0.13 cars compared to their anticipated level (significant at the $1 \%$ level).

Both models presented in Table 2 consistently indicate that free-floating car-sharing members reduce their level of car ownership compared to the control group. Yet the first model ignores initial intentions about a change in ownership level, while the second model assumes that there are no deviations from those initially stated intentions. To overcome the two models limitations, a simple population-averaged poisson model for the actual level of car ownership was estimated. The model equation is

$$
\ln E\left(y_{i t}\right)=\alpha+\delta_{t, 1} \gamma+\mathbf{x}_{\mathbf{i t}}^{\mathbf{T}} \beta, \quad y \sim \text { Poisson, }
$$

where $y_{i t}$ is the number of cars in the household of individual $i$ at time $t \in\{0,1\}$. $\alpha$ denotes the (time-invariant) constant and $\delta_{t, 1}$ is a dummy variable indicating observations from the second survey wave. $x_{i t}$ are the exogenous explanatory variables. Estimation is done using Generalized Estimating Equations [36]. The Poisson model was assumed appropriate, because the relative difference between $\mu_{y}=0.53$ and $\sigma_{y}^{2}=0.65$ was small. However, a regression-based test by Cameron and Trivedi [37] indicated significant overdispersion in the data $(t=-8.05)$. Therefore, the model was re-estimated as a population-averaged negative binomial model.

To improve efficiency, some covariates from the difference-in-differences models were dropped and replaced by new variables. This population-averaged model can be interpreted as explaining the average effect of free-floating car-sharing membership on its members' car-ownership level. The model is assumed to be the most suitable of the approaches presented in this section. The results are presented in Table 3 Indeed, parameter estimates for the negative binomial model are slightly different from the Poisson model, although differences are not substantial. In the following, interpretations are based on the negative binomial model. As presented in Table 3, the model indicates that university graduates and people living in areas well served by public transporta- 
Table 3: Population-Averaged Model for Car Ownership

\begin{tabular}{|c|c|c|c|c|}
\hline & \multicolumn{2}{|c|}{ Poisson } & \multicolumn{2}{|c|}{ neg. binomial } \\
\hline & Coeff. & $z$ & Coeff. & $z$ \\
\hline \multicolumn{5}{|l|}{ \# of cars in household } \\
\hline University degree & $-0.235^{*}$ & -1.94 & $-0.256^{* *}$ & -2.08 \\
\hline Household income [kCHF] & $0.029 * *$ & 2.48 & $0.028 * *$ & 2.34 \\
\hline Household size & $0.076^{*}$ & 1.71 & $0.080^{*}$ & 1.75 \\
\hline Home at transit level $\mathrm{A}$ & $-0.400 * * *$ & -3.30 & $-0.399 * * *$ & -3.27 \\
\hline Free-floating member & $-0.234^{* * *}$ & -4.13 & $-0.282^{* * *}$ & -4.49 \\
\hline Free-floating member \# car intentions & $0.688^{* * *}$ & 3.37 & $0.816^{* * *}$ & 4.37 \\
\hline Time dummy & $0.071^{*}$ & 1.79 & $0.080^{*}$ & 1.86 \\
\hline \multirow[t]{2}{*}{ Constant } & $-0.791^{* * *}$ & -4.18 & $-0.784^{* * *}$ & -4.08 \\
\hline & \multicolumn{2}{|c|}{$\begin{array}{c}N=790 \\
\text { Wald } \chi^{2}(7)=66.29^{* * *} \\
\text { pseudo } R^{2}=0.11\end{array}$} & \multicolumn{2}{|c|}{$\begin{array}{c}N=790 \\
\text { Wald } \chi^{2}(7)=76.71^{* * * *} \\
\text { pseudo } R^{2}=0.12\end{array}$} \\
\hline
\end{tabular}

pseudo $R^{2}$ calculated as the square of the correlation between predicted and actual values

tion own fewer private car 6 . In turn, car ownership increases with household income 7 These results are in line with earlier research on mobility tool ownership in Switzerland 38. The effect of free-floating car-sharing membership was then estimated separately for those respondents who claimed that they intended to buy an additional car and for those who planned no change in their car ownership. Members not planning to buy a car decreased their level of car ownership by about $24 \% 8$ members planning to buy a car substantially expanded their fleet. Thus, free-floating car-sharing generally reduces car ownership, except among members who had already planned to expand their fleet when they joined.

\footnotetext{
${ }^{6}$ Transit service levels as defined in the Swiss standard SN 640 290. Level A is the highest level of transit connectivity and requires a departure interval of, at most, 5 min per main load direction at rail stops in a $500 \mathrm{~m}$ perimeter

${ }^{7}$ Although university degree and income are correlated in this sample $(\rho=0.26)$, this correlation does not substantially affect the parameter estimate of free-floating car-sharing membership.

${ }^{8}$ Calculated as $e^{\beta \text { FFCS member }}-1$.
} 


\subsection{Free-floating Use Cases}

The second step consisted of a qualitative analysis of completed travel diaries to learn more about how free-floating car-sharing is used. To this end, all recorded days containing at least one free-floating car-sharing ride were identified. For each of those observations, a second recorded day with a similar activity chain, but without car-sharing use, was searched to allow a pairwise comparison ${ }^{9}$.

In total, 60 recorded days containing 96 free-floating car-sharing rides were available for the analysis. A corresponding trip without car-sharing use could be found on another day for only 17 of the 60 recorded days with car-sharing use. These trips mostly involved complex trip chains consisting of many (different) activities at multiple locations. This suggests that the scheme is mainly used for non-regular activity patterns, i.e. for activity patterns not occurring with frequent (at most weekly) repetition. In fact, $17 \%$ of all recorded free-floating car-sharing trips were leisure trips and $7 \%$ were escort trips. Shopping and errands covered another $11 \%$ of the trips. Recurring trip purposes, such as work or education, were served by only $13 \%$ of the trips. $40 \%$ of the trips had their destination home. $21 \%$ of the trips occurred at night between $10 \mathrm{pm}$ and 6 am. Moreover, $25 \%$ of the trips started or ended outside the service area, meaning that they were part of a tour including at least one more (return) free-floating trip. In fact, during half of the recorded days, free-floating car-sharing was used for more than one trip.

395

From the 17 car-sharing uses with a corresponding record, two typical use cases stand out. They are presented in Figure 2 .

- User type A (4 observations) is a long-haul commuter. They use free-floating carsharing on their commute to or from the train station, when they have to catch an early train or arrives home late. In the example presented in Figure 2 the train runs 40 minutes earlier than usual, which would involve an unfavourable tram connection on the first mile to the train station. $15 \%$ of the recorded trips either started or ended at the central train station.

- User type B (4 observations) is an occasional car user replacing his car use by both public transportation and free-floating car-sharing. In the example presented in Figure 2, he usually commutes to work by bike. When he had to go shopping on the way home, he usually took the car to work and shopped on the way home. After the launch of the free-floating car-sharing scheme, he continues to commute by bike. But on his shopping days, he takes public transportation to work and uses free-floating car-sharing to do the shopping on his way home.

The low number of observations permits only qualitative analysis. In particular, shares of trip purposes or times of day cannot be assumed to be representative for overall scheme use. Nevertheless, the data provides three interesting insights: first, free-floating car-sharing is mostly used for non-regular trip patterns. Second, if used in a regular trip pattern, it replaces both car and public transport trips, with the latter replaced

\footnotetext{
${ }^{9}$ For this purpose, all records of each respondent were compared manually. The main criterion was a similar sequence of activities.
} 

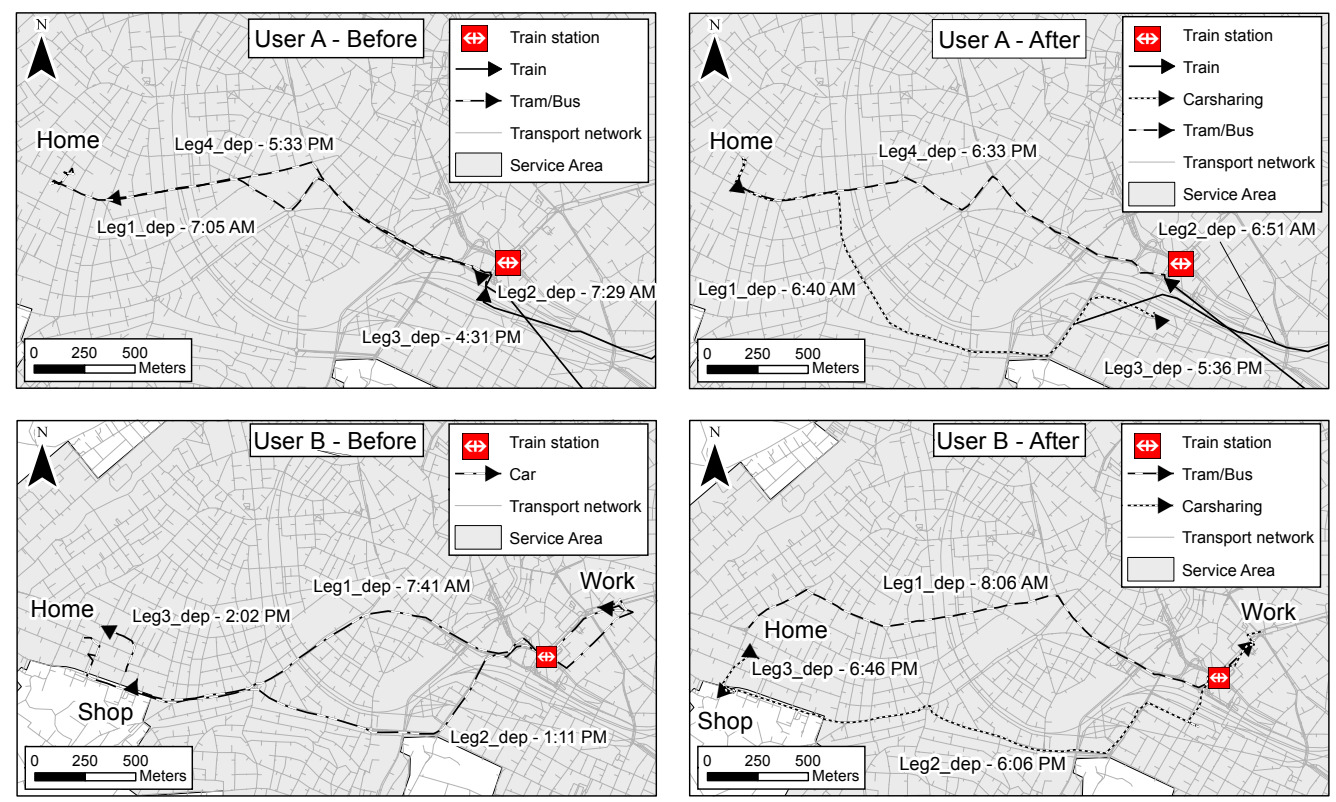

Figure 2: Car-Sharing Use for Regular Activities

mostly for early morning, late evening or longer intra-urban trips. Third, none of the free-floating car-sharing members was found to directly substitute active modes or public transport by free-floating car-sharing without any further alterations in the trip chain. 


\section{Discussion}

420 been conducted using retrospective surveys, which directly ask respondents about their current and past behavior as well as the degree to which car-sharing was the reason for potential changes [15. This strategy acknowledges that there are many (and often unknown) factors involved in travel behavior decisions and assumes that the respondents ${ }_{425}$ themselves are the most qualified to judge the impact their car-sharing membership had on their choices. Although this approach has its merits, it is also prone to recall bias, attribution bias, strategic responses and other limitations. This research aims to address such response biases by using a before-and-after comparison with quantitative travel behaviour data of both members and a control group. In this research, unobserved het-

430 erogeneity can be controlled for through a control group, whereas recall bias is eliminated through the two-wave approach, in which only information on present behavior is asked $\sqrt{10}$

Using this new appraoch, this research provides further insights into the travel behaviour impact of free-floating car-sharing, showing that free-floating car-sharing members reduce

435 their level of car-ownership. Model results indicate that free-floating car-sharing reduces the ex-ante car-ownership level of 0.27 vehicles per household by $24 \%$. This effect corresponds to a reduction of 0.06 vehicles per household or $6 \%$ of the member households reducing their level of car-ownership. The results are in line with earlier research 39 suggesting that impacts of free-floating car-sharing are weaker than those of station-based 440 car-sharing.

Notably, these model results also indicate a substantially lower impact than indicated in the survey, where $8 \%$ of free-floating car-sharing members stated that they would buy an (additional) car if free-floating car-sharing was not available 2. The car ownership ${ }_{445}$ impact in the model results is also lower than the observed change in vehicle holdings of 0.08 vehicles per household. This implies that the observed change in vehicle ownership cannot be entirely attributed to car-sharing membership. In addition, the analysis shows that using the intended level of car-ownership would lead to even more inflated results (reduction of 0.13 vehicles per household).

450

The model results are in line with results by [20, who reported a $5 \%$ reduction in household vehicle ownership for car2Go customers in Washington, DC. Although carownership impact of free-floating car-sharing is substantial, it is substantially lower than both early predictions for free-floating car-sharing by Firnkorn and Müller 18 and the widely accepted impact of station-based car-sharing, where $15-20 \%$ of all joining households are thought to have given up private car ownership [9], based on a (probably biased) stated-reduction approach.

Results from qualitative analysis of free-floating car-sharing use cases show that the scheme is mainly used for non-regular activities. In particular, a substantial share of freefloating trips are actually multi-stage or return trips, which indicates that free-floating

\footnotetext{
${ }^{10}$ Given that the first survey wave took place a few weeks after respondents had joined the free-floating car-sharing scheme, the resulting effects may be slightly underestimated. However, this bias is assumed to be small since car ownership decisions are usually not taken that fast.
} 
car-sharing is also used for trip patterns that would have been an original motivation for station-based car-sharing.

465 In the rare cases when free-floating car-sharing is used within a regular travel pattern, it does not directly substitute for public transport or active modes, except for connection with an earlier or later departure time, or other alterations to the routine. Yet, it allows some of its members to replace a car-only routine by both public transport and carsharing. Thus, the observations from travel diaries support the theory that free-floating 470 car-sharing does not necessarily lead to more car traffic. Also, these findings complement earlier research showing that free-floating car-sharing is used most often in situations, for which public transport is not attractive [40. Further, a substantial share of the freefloating car-sharing trips are multi-stage or round trips. Hence, it can be assumed that at least for shorter trips into the immediate surroundings of the city, the free-floating 475 car-sharing scheme not only complements, but partially competes with existing stationbased car-sharing schemes.

Although this research can determine the car-ownership impact of free-floating carsharing, significant results about mode choice and environmental impact could not be 480 obtained because of the small sample size. Given the substantial variation in individual travel behaviour, a sample size of about 300 valid travel diaries would have been required to more significantly determine the effect of free-floating car-sharing on car use and fuel consumption. 


\section{Conclusion}

Station-based car-sharing enables its members to shift from a car-oriented to a public transport-oriented lifestyle by providing a car on an as-needed basis 4. Given that free-floating car-sharing, due to its flexibility, is less predictable and therefore less reliable than station-based car-sharing from a customer's point of view, the question was; does it have a similar leverage effect on travel behaviour to station-based car-sharing? This research presents one of the first attempts to use quantitative, empirical data to address this question. It begins to confirm that free-floating car-sharing substantially and significantly reduces the level of car-ownership and triggers a modal shift towards public transportation.

In contrast, impacts on vehicle miles travelled and energy consumption could not be precisely determined due to the low number of valid travel diaries. Yet, when seen in light of the significant and substantial reduction in the level of car-ownership and the observation that none of the free-floating car-sharing members directly substituted active modes or public transportation with free-floating car-sharing, the results suggest that there is no net increase in car travel caused by free-floating car-sharing. Further research is also needed to quantify the impact on vehicle miles traveled and to better understand the causal nature of the reductions in car-ownership and (potentially) use.

However, already at this stage, the results provide policy-makers with a better understanding of free-floating car-sharing impacts. It was confirmed that - despite a slightly weaker impact than for station-based car-sharing - free-floating car-sharing also triggers a shift away from private vehicle ownership. Instead, it seems to complement a publictransportation oriented lifestyle. Given these positive impacts on the transportation system, some cities may find it easier to allow free-floating car-sharing operators access to the on-street parking places they need for their operations.

With respect to methodology, results suggest that the actual impact of a car-sharing scheme may be weaker than changes in car ownership or travel behaviour stated by its members in a retrospective survey. The difference is significant and stresses the importance of not solely relying on survey results for valid impact estimation. 


\section{Acknowledgements}

The study was commissioned by Mobility Switzerland and involved a parallel Swiss National Fund project (National Research Program 71: Managing Energy Consumption, project number 407140_153807). The authors thank the three anonymous reviewers for their valuable feedback.

\section{Appendix A. Impact of Car-Sharing membership on private vehicle holdings}

The following table provides an overview of selected studies estimating the impact of car-sharing schemes on their members' private vehicle holdings. The results were usually reported in three key numbers:

- reduction in car-ownership: What share of car-sharing members have reduced their private vehicle holdings due to their membership in the car-sharing scheme?

- foregone purchase of private car: Typically, members are asked, whether they would buy a private vehicle, if the car-sharing scheme was unavailable (or would suddenly disappear).

- replacement rate: How many private vehicles are replaced per car-sharing vehicle?

So far, there has not been a common procedure to estimate these numbers. While in some cases, the reported impact was weighted by the relative importance of car-sharing [15] or to account for intention-behavior gaps [18, in other cases, the plain responses were presented. Moreover, the two first numbers are sometimes added to obtain the combined impact on vehicle holdings. However, one would have to expect that this would result in double-counting of members, who have shed a car due to their car-sharing membership (and who would therefore likely buy a car in the absence of the scheme). 


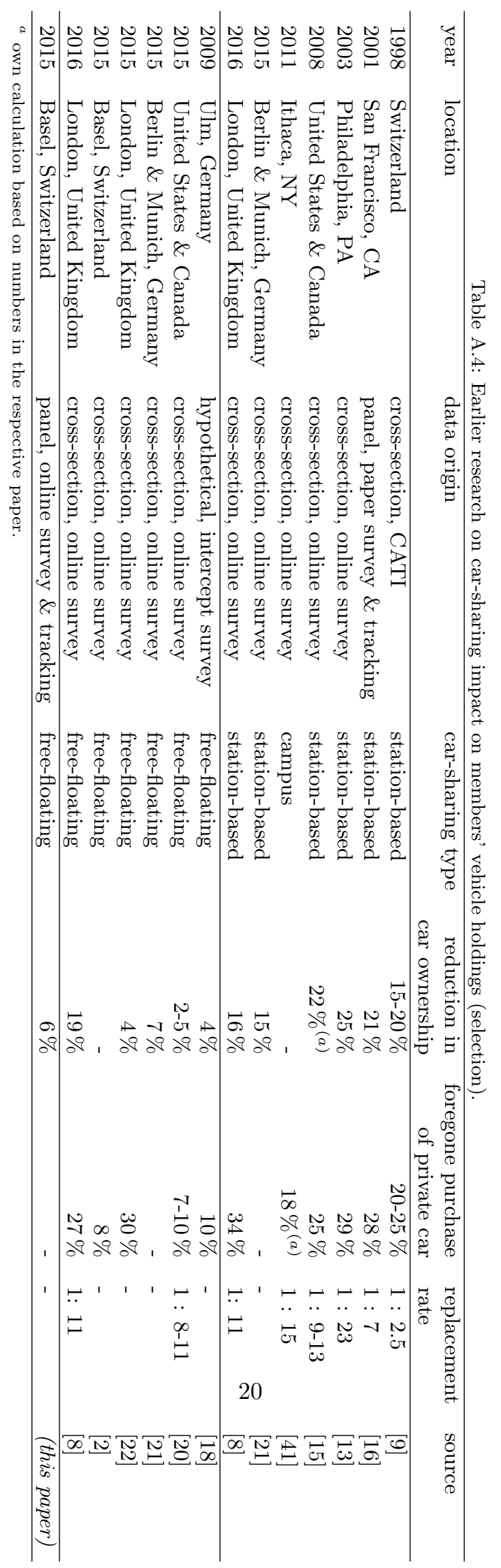




\section{References}

[1] S. A. Shaheen, N. D. Chan, H. Micheaux, One-way carsharing's evolution and operator perspectives from the Americas, Transportation 42 (2015) 519-536.

[2] H. Becker, F. Ciari, K. W. Axhausen, Comparing car-sharing schemes in Switzerland: User groups and usage patterns, Transportation Research Part A 97 (2017) 17-29.

[3] Seattle Department of Transportation, 2013 Seattle Free-Floating Car Share Pilot Program Report, Tech. rep., Seattle Department of Transportation, Seattle (2014).

[4] S. A. Shaheen, A. P. Cohen, Carsharing and Personal Vehicle Services: Worldwide Market Developments and Emerging Trends, International Journal of Sustainable Transportation 7 (2013) $5-34$.

[5] T. Litman, Evaluating Carsharing Benefits, Transportation Research Record 1702 (2000) 31-35.

[6] S. Le Vine, M. Lee-Gosselin, A. Svakumar, J. Polak, A new approach to predict the market and impacts of round-trip and point-to-point carsharing systems: Case study of London, Transportation Research Part D 32 (2014) 218-229.

[7] E. Martin, S. Shaheen, Greenhouse gas emission impacts of carsharing in North America Intelligent Transportation Systems 12 (4) (2011) 1074-1086. URL http://ieeexplore.ieee.org/xpls/abs\{_\}all.jsp?arnumber=5951778

Steer Davies Gleave, Carplus Annual Survey of Car Clubs 2016/2017, Tech. rep., Leeds (2017).

[9] P. Muheim, E. Reinhardt, Carsharing: The key to combined mobility, World Transport, Policy \& Practice 5 (3) (1999) 58-71.

[10] G. S. Mishra, R. Clewlow, P. Mokhtarian, Effect of Carsharing on Vehicle Holdings and Travel Behavior: Propensity Score and Causal Mediation Analysis of San Francisco Bay Area, in: 95th Annual Meeting of the Transportation Research Board, Washington, D.C., 2016.

[11] J. A. Kopec, J. M. Esdaile, Bias in case-control studies. A review, J Epidemiol Community Health 44 (3) (1990) 179-186.

[12] P. L. Mokhtarian, X. Cao, Examining the Impacts of Residential Self-selection on Travel Behavior: A Focus on Methodologies, Transportation Research Part B 42 (3) (2008) 204-228.

13] C. Lane, PhillyCarShare - First-year social and mobility impacts of carsharing in Philadelphia, Pennsylvania, Transportation Research Record 1927 (2005) 158-166.

[14] C. Rydén, E. Morin, Environmental assessment: Report WP 6, Tech. rep., Trivector Traffic, Stockholm (2005).

[15] E. Martin, S. A. Shaheen, J. Lidicker, Impact of Carsharing on Household Vehicle Holdings, Transportation Research Record 2143 (2010) 150-158.

[16] R. Cervero, Y. Tsai, City CarShare in San Francisco, California: Second-Year Travel Demand and Car Ownership Impacts, Transportation Research Record 1887 (2004) 117-127.

[17] R. Cervero, A. Golub, B. Nee, City CarShare: Longer-Term Travel Demand and Car Ownership Impacts, Transportation Research Record 1992 (2007) 70-80.

[18] J. Firnkorn, M. Müller, What will be the environmental effects of new free-floating car-sharing systems? The case of car2go in Ulm, Ecological Economics 70 (8) (2011) 1519-1528.

[19] J. Firnkorn, Triangulation of two methods measuring the impacts of a free-floating carsharing system in Germany, Transportation Research Part A 46 (10) (2012) 1654-1672. URL http://dx.doi.org/10.1016/j.tra.2012.08.003

580 [20] E. Martin, S. A. Shaheen, Impacts of car2go on Vehicle Ownership, Modal Shift, Vehicle Miles Travelled, and Greenhouse Gas Emissions: An Analysis of Five North American Cities, Tech. rep., Transportation Sustainability Research Center (TSRC), Berkeley (2016).

[21] F. Giesel, C. Nobis, The Impact of Carsharing on Car Ownership in German Cities, Transportation Research Procedia 19 (2016) 215-224.

585 [22] S. Le Vine, J. Polak, The impact of free-floating carsharing on car ownership: Early-stage findings from London, Transport Policy.

[23] S. Bricka, C. R. Bhat, A comparative analysis of GPS-based and travel survey-based data, Transportation Research Record 1972 (2006) 9-20.

[24] P. Stopher, C. FitzGerald, M. Xu, Assessing the accuracy of the Sydney Household Travel Survey with GPS, Transportation 34 (6) (2007) 723-741. doi:10.1007/s11116-007-9126-8

[25] L. Montini, N. Rieser-Schüssler, K. W. Axhausen, Field Report: One-Week GPS-based Travel Survey in the Greater Zurich Area, in: Swiss Transport Research Conference, Monte Verita, 2013.

[26] L. Wargelin, P. Stopher, J. Minser, K. Tierney, M. Rhindress, S. O'Connor, GPS-Based Household Interview Survey for the Cincinnati Ohio Region, Tech. rep., Abt SRBI Inc., New York (2012)

[27] M. G. S. Oliveira, P. Vovsha, J. Wolf, Y. Birotker, D. Givon, J. Paasche, Global Positioning System- 
Assisted Prompted Recall Household Travel Survey to Support Development of Advanced Travel

17. Model in Jerusalem, Israel, Transportation Research Record 2246 (2011) 16-23. doi:10.3141/ 2246-03

600

[28] C. D. Cottrill, F. C. Pereira, F. Zhao, I. F. Dias, H. B. Lim, M. E. Ben-Akiva, P. C. Zegras, The Future Mobility Survey: Experiences in developing a smartphone-based travel survey in Singapore Transportation Research Record 2354 (2013) 59-67.

URL http://dx.doi.org/10.3141/2354-07

[29] J. Kopp, R. Gerike, K. W. Axhausen, Do sharing people behave differently? An empirical evaluation of the distinctive mobility patterns of free-floating car-sharing members Transportation 42 (2015) 449-469. doi :10.1007/s11116-015-9606-1

URL http://link.springer.com/10.1007/s11116-015-9606-1

[30] BMW AG, DLR, DB Rent GmbH, Landeshauptstadt München, Universität der Bundeswehr München, Senatsverwaltung für Stadtentwicklung und Umwelt Berlin, Wirkung von E-Car Sharing Systemen auf Mobilität und Umwelt in urbanen Räumen (WiMobil), Tech. rep. (2016).

31] Planungsbro Jud, Stdtevergleich Mobilitt Tech. rep., Basel-Stadt, Stadt Bern, Stadt Luzern, Stadt St.Gallen, Stadt Winterthur and Stadt Zrich (eds.), Kloten (2012).

URL WwW.bs.ch/dms/mobilitaet/download/flyup-publikation/06_staedtevergleich_ mobilitaet.pdf

[32] K. W. Axhausen, B. Schmid, C. Weis, Predicting response rates updated, Tech. Rep. 1063, Institute for Transport Planning and Systems, ETH Zurich (2015).

[33] Swiss Federal Statistical Office (BFS) and Swiss Federal Office for Spatial Development (ARE), Mobilität in der Schweiz - Ergebnisse des Mikrozensus Mobilität und Verkehr 2010, Swiss Federal Statistical Office (BFS) and Swiss Federal Office for Spatial Development (ARE), Neuchatel and Berne (2012).

620 [34] A. C. Cameron, K. Trivedi, Pravin, Count Panel Data, in: B. H. Baltagi (Ed.), The Oxford Handbook of Panel Data, Oxford University Press, Oxford, 2015, Ch. 8.

[35] M. van Eggermond, A. Erath, K. W. Axhausen, Vehicle Ownership and Usage in Switzerland: Role of Micro- and Macroaccessibility, in: 95th Annual Meeting of the Transportation Research Board, Washington, D.C., 2016.

625 [36] K.-Y. Liang, S. L. Zeger, Longitudinal data analysis using generalized linear models, Biometrica 73 (1986) $13-22$.

[37] C. Cameron, P. Trivedi, Regression-based tests for overdispersion in the Poisson model, Journal of Econometrics 46 (1990) 347-364.

[38] H. Becker, A. Loder, B. Schmid, K. W. Axhausen, Modeling car-sharing membership as a mobility tool: A multivariate Probit approach with latent variables, Travel Behaviour and Society 8 (2017) 26-36.

[39] S. Le Vine, O. Adamou, J. Polak, Predicting new forms of activity/mobility patterns enabled by shared-mobility services through a needs-based stated-response method: Case study of grocery shopping, Transport Policy 32 (2014) 60-68.

URL http://dx.doi.org/10.1016/j.tranpol.2013.12.008

[40] H. Becker, F. Ciari, K. W. Axhausen, Modelling free-floating car-sharing use in Switzerland: A spatial regression and conditional logit approach, Transportation Research Part C 81 (2017) 286299.

[41] T. H. Stasko, A. B. Buck, H. O. Gao, Carsharing in a university setting: Impacts on vehicle ownership, parking demand, and mobility in Ithaca, NY, Transport Policy 30 (2013) 262-268. 